\title{
Significance of cyclooxygenase-2, prostaglandin E2 and CD133 levels in sunitinib-resistant renal cell carcinoma
}

\author{
LEI LUO ${ }^{1}$, YE LIANG ${ }^{2}$, XUEMEI DING ${ }^{3}$, XIAOCHENG MA $^{1}$, GUIMING ZHANG $^{1}$ and LIJIANG SUN ${ }^{1}$ \\ ${ }^{1}$ Department of Urology; ${ }^{2}$ Key Laboratory, Department of Urology and Andrology; ${ }^{3}$ Operating Room, \\ The Affiliated Hospital of Qingdao University, Qingdao, Shangdong 266003, P.R. China
}

Received April 28, 2018; Accepted April 24, 2019

DOI: $10.3892 / \mathrm{ol} .2019 .10442$

\begin{abstract}
The current study investigated the mechanism underlying sunitinib resistance. The parental human renal cell carcinoma ( $\mathrm{RCC}$ ) cell line 786-O was continuously exposed to various doses of sunitinib to obtain sunitinib-resistant cells (786-O/S). Cell proliferation and colony formation assays were performed to assess the survival of $786-\mathrm{O} / \mathrm{S}$ cells. The half-inhibitory concentration for the drug-resistant cells was calculated. 786-O/S cells demonstrated notably morphological changes compared with parental cells. Compared with 786-O cells, 786-O/S cells exhibited stronger proliferative and colony-forming abilities. Western blot analysis was performed to measure the levels of cyclooxygenase 2 (COX-2) and prostaglandin E2 (PGE2). Reverse transcription-quantitative polymerase chain reaction (RT-qPCR) was used to detect the expression of COX-2 and cluster of differentiation (CD) 133 in both 786-O and 786-O/S cells. Following incubation of the two cell lines with celecoxib, a COX-2 inhibitor, RT-qPCR was performed to detect the expression of COX-2 and CD133, and western blot analysis was used to assess the expression of $\mathrm{CD} 133$. The results revealed that the levels of COX-2 and PGE2 were significantly higher in 786-O/S cells compared with 786-O cells $(\mathrm{P}<0.01)$. Similarly, the expression of CD133 was 24-fold higher in 786-O/S compared with the parental cells $(\mathrm{P}<0.01)$. When celecoxib was incubated with the two cell lines, the expression of COX-2 and CD133 decreased significantly $(\mathrm{P}<0.0001)$. In summary, the results indicate that activation of the COX-2-PGE2 pathway in RCC leads to the development of sunitinib resistance and may serve an important role in the maintenance of the characteristics of stem cells that are closely associated with drug resistance.
\end{abstract}

Correspondence to: Dr Lijiang Sun or Dr Guiming Zhang, Department of Urology, The Affiliated Hospital of Qingdao University, 16 Jiangsu Road, Qingdao, Shandong 266003, P.R. China E-mail: slijiang999@126.com

E-mail: zhangguiming9@126.com

Key words: sunitinib resistance, renal cell carcinoma, cluster of differentiation 133, cyclooxygenase-2, prostaglandin E2

\section{Introduction}

Renal cell carcinoma (RCC) is the second most common type of cancer of the urological system and represents 2-3\% of all adult cancer cases (1). Clear cell RCC is the primary subtype of RCC and accounts for $70-80 \%$ of all cases (1). In recent years, there has been an increase in the rates of RCC-associated morbidity and mortality (2). Given the absence of specific clinical manifestations, including local pain and hematuria, $20-30 \%$ of patients with RCC possess metastatic disease at the time of diagnosis and $20 \%$ of patients relapse with metastasis following surgical intervention $(2,3)$. RCC is highly resistant to conventional cytotoxic chemotherapy and immunotherapy offers unsatisfactory improvement in survival (4). The prognosis of metastatic RCC (mRCC) is poor, with a 5-year survival rate $<5 \%$ (5). In the last decade, the introduction of several targeted therapies has improved the treatment of mRCC. Among a number of molecularly-targeted agents, sunitinib is regarded as a powerful therapeutic agent against mRCC (6). Sunitinib is an oral multi-target tyrosine kinase inhibitor that acts on vascular endothelial growth factor receptor (VEGFR)-1, VEGFR-2, Fms-like tyrosine kinase receptor 3, c-KIT and platelet-derived growth factor receptor $(7,8)$. A large-scale randomized phase III trial (SU11248) comparing sunitinib with interferon in patients with mRCC demonstrated a significantly higher objective response rate (31 vs. 6\%) and longer progression-free survival time (11 vs. 5 months) for the sunitinib-treated group (HR, 0.42; CI, 0.32-0.54) (9). However, tumor cells gradually become refractory and drug resistance is inevitable following sunitinib treatment for a certain period (5).

Cyclooxygenase 2 (COX-2) is a key enzyme that stimulates the production of prostaglandin E2 (PGE2) and arachidonic acid. COX-2 serves a role in the inflammation, growth, invasiveness and metastasis of a tumor, and inhibits apoptosis and angiogenesis (9). However, to the best of our knowledge, the involvement of COX-2 in $\mathrm{RCC}$ drug resistance remains unknown. Celecoxib, a selective $\mathrm{COX}-2$ inhibitor, is a clinically effective drug as it can inhibit COX enzymes and consequently prevent, inhibit or abrogate the effects of prostaglandins (10). Previous studies have reported the antitumor effect of celecoxib against RCC $(11,12)$.

Cancer stem cells (CSCs) are important for cancer progression (13). CSCs are a small subpopulation of cells that exhibit stem-like properties, which are associated with the initiation, 
chemoresistance, metastasis and recurrence of cancer (13). CSCs express several specific markers that may facilitate the isolation and identification of CSCs, including cluster of differentiation (CD) 133, which is widely expressed (14). CD133, also termed prominin 1 , is a $120 \mathrm{kDa}$ transmembrane glycoprotein that is recognized as a useful marker for the identification and isolation of CSCs from many types of solid tumors, including colon, brain, lung, liver, prostate, skin and kidney cancer (15).

A number of studies have elucidated the molecular mechanism underlying sunitinib resistance in RCC (7-9); however, this mechanism remains largely unclear. The present study established a human RCC cell line that was resistant to sunitinib and analyzed the changes in COX-2, PGE2 and CD133 expression to identify potential targets for overcoming acquired resistance to sunitinib.

\section{Materials and methods}

Materials and reagents. The human $\mathrm{RCC}$ cell line 786-O was obtained from the American Type Culture Collection (Manassas, VA, USA). Sunitinib and 3-(4, 5-dimethylthiazol-2-yl)-2,5-diphenyl tetrazolium bromide (MTT) were purchased from Sigma-Aldrich; Merck KGaA (Darmstadt, Germany). Materials for cell culture, including RPMI-1640 medium, trypsin and $10 \%$ fetal bovine serum (FBS) were obtained from Gibco (Thermo Fisher Scientific, Inc., Waltham, MA, USA). All other reagents were of reagent grade.

Determination of the half-inhibitory concentration $\left(I C_{50}\right)$ of sunitinib for the RCC cell line 786-O. The 786-O cell line was cultured at $37^{\circ} \mathrm{C}$ in the RPMI-1640 medium supplemented with $10 \%$ of FBS. Upon reaching their logarithmic growth phase, the cells were seeded in 96-well culture plates at optimal density $\left(10^{4}\right.$ cells/well $)$ and incubated in a $5 \% \mathrm{CO}_{2}$ incubator at $37^{\circ} \mathrm{C}$. The cells were cultured for $24 \mathrm{~h}$ and the medium of the experimental group was supplemented with different concentrations $(0.5,1,2.5,5$ or $15 \mu \mathrm{M})$ of sunitinib at $37^{\circ} \mathrm{C}$. Media with the same concentrations of sunitinib but without cells were used as the drug blank controls. Cells with the culture medium alone served as the control and wells with the culture medium alone were designated as the normal blank group. Five parallel wells were included in each group. Following $72 \mathrm{~h}$ of treatment, MTT $(20 \mu \mathrm{l})$ was added to each well and incubated for an additional $4 \mathrm{~h}$ at $37^{\circ} \mathrm{C}$. The formazan precipitate was dissolved in $150 \mu \mathrm{l}$ dimethyl sulfoxide and the absorbance at $490 \mathrm{~nm}$ was measured on a microplate reader to provide the optical density (OD). The relative growth rate (RGR) was calculated as follows: RGR $(\%)=\left(\mathrm{OD}_{\mathrm{e}}-\mathrm{OD}_{\mathrm{e} 0}\right) /\left(\mathrm{OD}_{\mathrm{c}}-\mathrm{OD}_{\mathrm{c} 0}\right) \times 100 \%$, where $\mathrm{OD}_{\mathrm{e} 0}, \mathrm{OD}_{\mathrm{c} 0}, \mathrm{OD}_{\mathrm{e}}$ and $\mathrm{OD}_{\mathrm{c}}$ represent the absorbance of the drug blank, normal blank, experimental group and control group, respectively. A cell survival curve was plotted as the mean value of each group; the $\mathrm{IC}_{50}$ was calculated following curve fitting.

Creation of a sunitinib-resistant RCC cell line. According to the results of $\mathrm{IC}_{50}$ evaluation, an RCC cell line demonstrating resistance to sunitinib, termed $786-\mathrm{O} / \mathrm{S}$, was generated by serial treatment of the parental 786-O cell line with various concentrations of sunitinib from 2.5 to $10 \mu \mathrm{M}$ at $37^{\circ} \mathrm{C}$ with the dose given at 1 month intervals. Following continuous culture in the complete medium supplemented with $10 \mu \mathrm{M}$ sunitinib for $>10$ passages, identify the $\mathrm{IC}_{50}$ of $786 \mathrm{O} / \mathrm{S}$ cells with method mentioned above (concentrations of sunitinib, 5, 10, 15, 20, 30, 40 and $50 \mu \mathrm{M}$ ). The cells were employed as sunitinib-resistant RCC cells in all subsequent experiments.

Cell migration analysis. 786-O and 786-O/S cells were cultured in RPMI-1640 supplemented with $10 \% \mathrm{FBS}$ at $37^{\circ} \mathrm{C}$ and $5 \%$ $\mathrm{CO}_{2}$ in a humidity-saturated incubator. Upon reaching their logarithmic growth phase, the cells were seeded in 12-well culture plates at optimal density $\left(10^{5}\right.$ cells/well $)$ and kept in the $5 \% \mathrm{CO}_{2}$ incubator at $37^{\circ} \mathrm{C}$ overnight. Following culture, the cells were incubated at $37^{\circ} \mathrm{C}$ with RPMI-1640 without FBS for $>4$ h to obtain cells in the same growth phase. Subsequently, a scratch was created using a $200 \mu \mathrm{l}$ tip. The culture medium was replaced with culture medium containing $6 \mu \mathrm{M}$ sunitinib and images of the cells were obtained using a fluorescence microscope (x40 magnification) at 0,24 and $48 \mathrm{~h}$.

Colony formation ability. To detect the effects of sunitinib on colony formation ability, 786-O and 786-O/S cells were seeded in 6-well culture plates at 1,000, 500 and 200 cells/well. Following $24 \mathrm{~h}$ at $37^{\circ} \mathrm{C}$, culture medium containing $6 \mu \mathrm{M}$ sunitinib was added to each well and cells were cultured for 15 days at $37^{\circ} \mathrm{C}$ with $5 \% \mathrm{CO}_{2}$. During this time, the medium was refreshed every 3 days. Subsequently, the cells were washed three times at $37^{\circ} \mathrm{C}$ with $\mathrm{PBS}$, fixed with $4 \%$ paraformaldehyde for $15 \mathrm{~min}$ at room temperature and washed three times with distilled water. The cells were then stained with $0.5 \%$ crystal violet $(5 \mathrm{mg} / \mathrm{ml})$ for $15 \mathrm{~min}$ at room temperature, followed by washing with distilled water. The colonies stained with crystal violet were counted.

Western blot analysis of COX-2 and PGE2. Both 786-O and $786-\mathrm{O} / \mathrm{S}$ cell lines were seeded in 24 -well culture plates in culture medium alone or with $6 \mu \mathrm{M}$ sunitinib for $72 \mathrm{~h}$ at $37^{\circ} \mathrm{C}$. Total protein was extracted from cells using SDS lysis buffer (Beyotime Institute of Biotechnology, Shanghai, China). Protein concentration was determined with a Bicinchoninic Acid Protein assay kit (Thermo Fisher Scientific, Inc.). Samples containing $30 \mu \mathrm{g}$ of protein were subjected to SDS-polyacrylamide gel (4\% stacking gel and 10\% separating gel) electrophoresis and the protein bands were then transferred onto a polyvinylidene difluoride membrane. The membrane was blocked for $1 \mathrm{~h}$ at room temperature with $5 \%$ fat-free milk in Tris-buffered saline containing $0.1 \%$ Tween-20 and incubated overnight with primary antibodies at $4^{\circ} \mathrm{C}$. The primary antibodies included those against human COX-2 (Cell Signaling Technology, \#12282, 1:1,000), PGE2 (Absin Bioscience, www.absin.cn, abs124338, 1:1,000) and GAPDH (Sigma-Aldrich, G9545, 1:5,000). The following day the blots were incubated with the goat-anti-rabbit and goat-anti-mouse antibody (Jackson ImmunoResearch, 111-035-045 and 115-035-062, 1:10,000) at room temperature for $1 \mathrm{~h}$. Specific binding was detected using an enhanced chemiluminescenct kit (Pierce; Thermo Fisher Scientific, Inc.).

Detection of CSC marker proteins and COX-2 by reverse transcription-quantitative polymerase chain reaction ( $R T-q P C R)$. Both 786-O and 786-O/S cells were cultivated in 24-well culture plates for $48 \mathrm{~h}$. Total RNA was extracted from the cells using 
RNAiso Plus (Takara Bio, Inc., Otsu, Japan). To detect mRNA, complementary DNA was synthesized from the total RNA with SuperScript Reverse Transcriptase (Takara Bio, Inc.) according to the manufacturer's protocols and then mRNA was detected with SYBR Primer Ex Tag II (Takara Bio, Inc.). The primers targeting CD133, COX-2 and GAPDH were as follows: CD133 forward, 5'-TTGTGGCAAATCACCAGGTA and reverse, 5'-TCAGATCTGTGAACGCCTTG; COX-2 forward, 5'-GCA CAAATATGATGTTCGCATT and reverse, 5'-CTGAACCCA GGTCCTCGCTTCT; and GAPDH forward, 5'-TCATGGGTG TGAACCATGAGAA and reverse, 5'-GGCATGGACTGTGGT CATGAG-3'. qPCR was performed on a Roche 480 machine (Roche Diagnostics GmbH, Mannheim, Germany) with the following parameters: One cycle at $95^{\circ} \mathrm{C}$ for $10 \mathrm{~min}$, followed by 40 cycles of $95^{\circ} \mathrm{C}$ for $15 \mathrm{sec}$ and $60^{\circ} \mathrm{C}$ for $1 \mathrm{~min}$. Each group was set 3 parallel well and the quantification cycle values were calculated for all genes with $2^{-\Delta \Delta \mathrm{Cq}}$ method (16).

Detection of COX-2 and CD133 by qPCR in the celecoxib condition. Both 786-O and 786-O/S cell lines were seeded in 24-well culture plates in the culture medium alone or culture medium containing $6 \mu \mathrm{M}$ sunitinib for $48 \mathrm{~h}$ incubation at $37^{\circ} \mathrm{C}$. Different concentrations of celecoxib $(10$ or $25 \mu \mathrm{M})$ were added to each well for $24 \mathrm{~h}$. The experimental procedure for RT-qPCR was then performed as aforementioned.

Detection of CD133 by western blot analysis in the celecoxib condition. Both 786-O and 786-O/S cell lines were seeded in 24-well plates in the culture medium alone or culture medium containing $6 \mu \mathrm{M}$ sunitinib for $48 \mathrm{~h}$ incubation at $37^{\circ} \mathrm{C}$. Different concentrations of celecoxib $(10$ or $25 \mu \mathrm{M})$ were added to each well. The anti-human CD133 antibody was purchased from Cell Signaling Technology, Inc. (\#64326, 1:1,000). The experimental procedure for western blot analysis was then performed as aforementioned.

Statistical analysis. Experiments were performed three times and data are presented as the mean \pm standard error of the mean. Data were analyzed using SPSS 18.0 software (SPSS, Inc., Chicago, IL, USA). Comparisons were performed by an unpaired Student t-test for two groups and one-way analysis of variance for more than two groups. Comparisons between multiple groups was performed using $\mathrm{S}-\mathrm{N}-\mathrm{K}$ method. $\mathrm{P}<0.05$ was considered to indicate a statistically significant difference. The results were statistically analyzed by GraphPad software V.8 (GraphPad Software, Inc., La Jolla, CA, USA).

\section{Results}

$I C_{50}$ of sunitinib for 786-O cells. To evaluate the effects of different concentrations $(0,0.5,1,2.5,5$ or $15 \mu \mathrm{M})$ of sunitinib on the viability of 786-O cells an MTT assay was performed. The mean value of each group at $490 \mathrm{~nm}$ decreased with increases in sunitinib concentration (Table I). Based on these data, RGR values were calculated and cell survival curves were plotted. The $\mathrm{IC}_{50}$ value was calculated following curve fitting and identified to be $8.15 \mu \mathrm{M}$ (Fig. 1).

Development of the sunitinib-resistant RCC cell line (786-O/S). When 786-O cells were treated with various concentrations
Table I. Mean value of the optical density at $490 \mathrm{~nm}$ for $786-\mathrm{O}$ cells treated with different concentrations of sunitinib for $72 \mathrm{~h}$.

\begin{tabular}{lc} 
Sunitinib $(\mu \mathrm{M})$ & Mean \pm standard deviation \\
\hline 0.0 & $0.6190 \pm 0.0269$ \\
0.5 & $0.5625 \pm 0.0365$ \\
1.0 & $0.5697 \pm 0.03451$ \\
2.5 & $0.5273 \pm 0.03519$ \\
5.0 & $0.4647 \pm 0.02996$ \\
15.0 & $0.0421 \pm 0.00652$
\end{tabular}

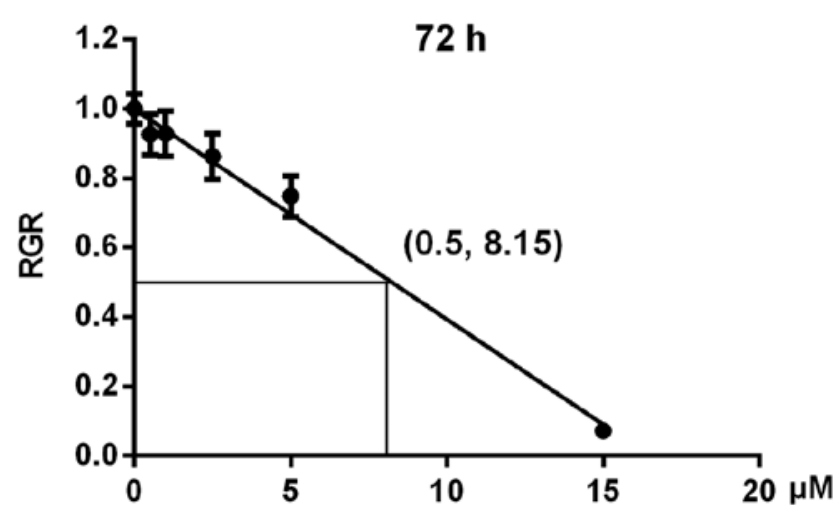

Figure 1. Cell survival curve plotted according to the RGR of 786-O cells treated with different concentrations of sunitinib for $72 \mathrm{~h}$. Following curve fitting, the half-inhibitory concentration was calculated as $8.15 \mu \mathrm{M}$. RGR, relative growth rate.

of sunitinib from 2.5 to $10 \mu \mathrm{M}$, morphological changes were observed (Fig. 2). In comparison with the control cells, sunitinib-resistant cells appeared slimmer with increasing drug concentration (Fig. 2A). Following continuous culture in complete culture medium supplemented with $10 \mu \mathrm{M}$ sunitinib for $>10$ passages, the $\mathrm{IC}_{50}$ determined by an MTT assay was $24.57 \mu \mathrm{M}$. According to the $\mathrm{IC}_{50}$ values for $786-\mathrm{O}$ and $786-\mathrm{O} / \mathrm{S}$ cells, the resistance index $\left(\mathrm{IC}^{\circ} 0_{786-\mathrm{O} / \mathrm{S}} / \mathrm{IC} 0_{786-\mathrm{O}}\right)$ was identified to be 3.01. These results demonstrated that drug resistance of 786-O/S cells significantly increased following treatment with high concentrations of sunitinib.

Cell migration assay for 786-O and 786-O/S cells. The migration of 786-O and 786-O/S cells was observed and photographed following treatment with $6 \mu \mathrm{M}$ sunitinib. As demonstrated in Fig. 3, the scratch area was significantly larger for 786-O cells compared with 786-O/S cells at 24 and $48 \mathrm{~h}$, indicating that the migration speed of 786-O/S cells was faster compared with that of the parental cells. The width of the scratch was significantly reduced in the $786-\mathrm{O} / \mathrm{S}$ cell group at $48 \mathrm{~h}$ compared with 786-O cells. Therefore, the migration ability of sunitinib-resistant cells was significantly promoted compared with the parental cells.

Proliferative ability of 786-O and 786-O/S cells. A colony formation assay was performed to analyze the proliferative ability of 786-O and 786-O/S cells. The cells were stained with crystal violet following culture with $6 \mu \mathrm{M}$ sunitinib for 
A
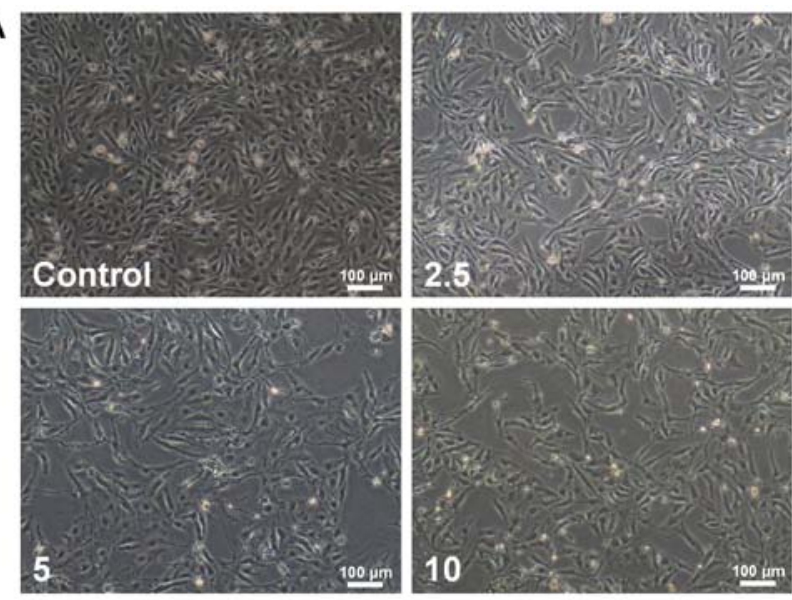

$72 \mathrm{~h}$

B

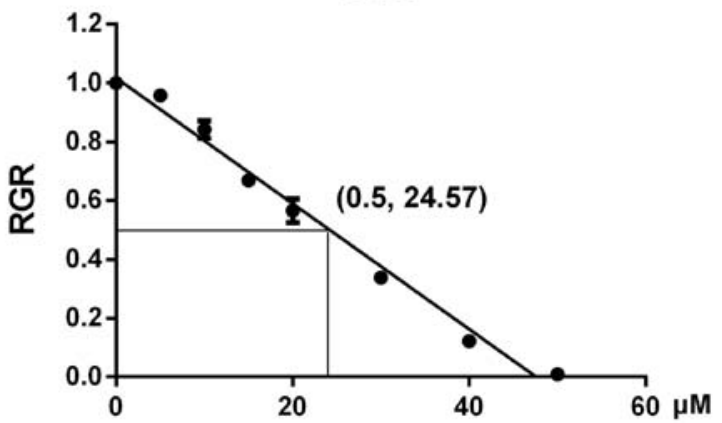

Figure 2. Morphological changes observed under a microscope and the $\mathrm{IC}_{50}$ value of 786-O/S cells. (A) Microscopic images of 786-O cells treated with $2.5,5.0$ or $10 \mu \mathrm{M}$ sunitinib. Scale bar, $100 \mu \mathrm{m}$. (B) An $\mathrm{IC}_{50}$ value was calculated following treatment of the cells with $10 \mu \mathrm{M}$ sunitinib for $>10$ passages. IC $_{50}$, half-inhibitory concentration; RGR, relative growth rate; 786-O/S, sunitinib-resistant 786-O.

15 days. When observed directly, the number of colonies of 786-O/S cells was greater and the size of the colonies was larger compared with that of 786-O cells in the 1,000-, 500and 200-cell groups (Fig. 4A). This was consistent with the quantified analysis results, which revealed a significantly higher number of colonies in the 786-O/S group compared with the control (Fig. 4B). The colony formation ability of the cells notably decreased following treatment with $6 \mu \mathrm{M}$ sunitinib (Fig. 4). Therefore, sunitinib-resistant cells demonstrated a significant increase in proliferative ability.

Expression of COX-2 and PGE2 in 786-O and 786-O/S cells. The expression levels of COX-2 and PGE2 in 786-O and 786-O/S cells were quantified following western blot analysis (Fig. 5), which revealed significantly higher expression levels of COX-2 (Fig. 5B) and PGE2 (Fig. 5C) in 786-O/S cells compared with 786-O cells.

Expression of COX-2 and $\mathrm{CD} 133$ in 786-O and 786-O/S cells. The mRNA expression levels of COX-2 in 786-O and 786-O/S cells were quantified by RT-qPCR. The results demonstrated that the expression levels of $\mathrm{COX}-2$ in $786-\mathrm{O} / \mathrm{S}$ cells were higher compared with the control cells (Fig. 6A; $\mathrm{P}<0.01$ ). CD133, an important CSC marker in RCC, was used to examine the stemness of 786-O/S cells. The expression levels of CD133 in 786-O/S cells were higher compared with that
A
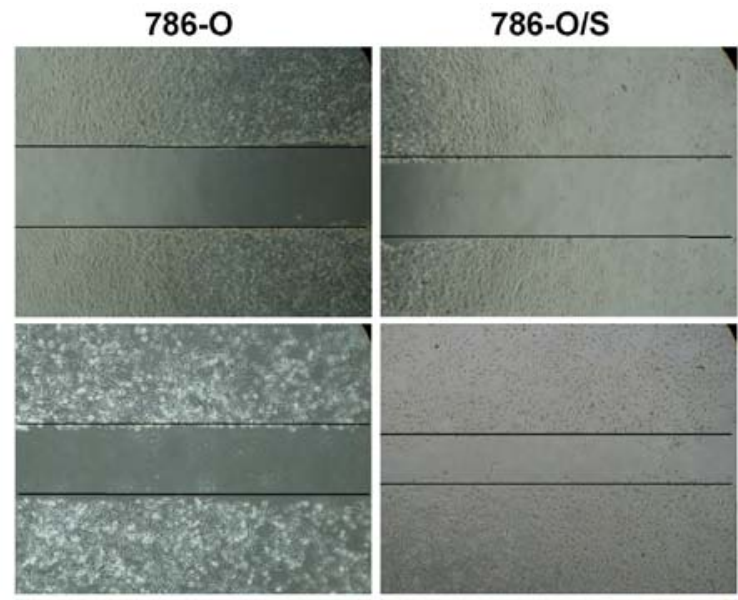

$48 \mathrm{~h}$
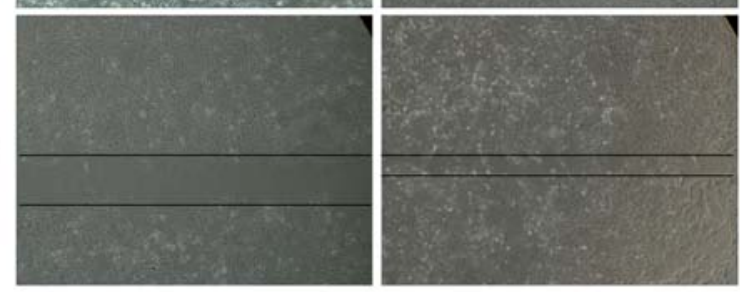

B

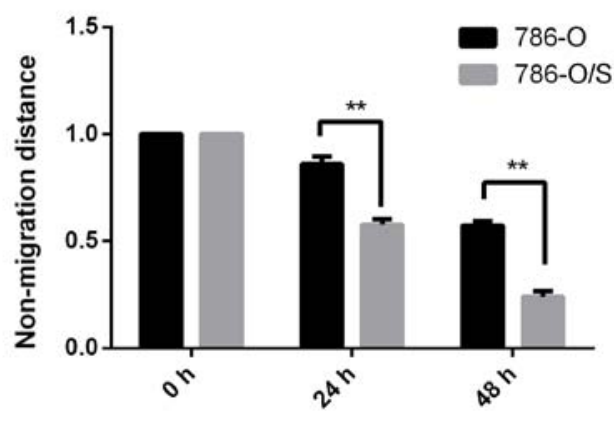

Figure 3. Effects of sunitinib on the migration of $786-\mathrm{O}$ and $786-\mathrm{O} / \mathrm{S}$ cells. (A) Observation under a microscope (x40 magnification). (B) Statistical analysis of the decrease in migration distance. Data are presented as the mean \pm standard error of the mean. ${ }^{* *} \mathrm{P}<0.01$. 786-O/S, sunitinib-resistant 786-O.

in the control cells (Fig. 6B). When different concentrations $(10$ or $25 \mu \mathrm{M})$ of celecoxib were incubated with the cells, the expression levels of COX-2 significantly decreased at both concentrations $(\mathrm{P}<0.001)$. In addition, a significant decrease in the expression of CD133 was observed following treatment with $10 \mu \mathrm{M}(\mathrm{P}<0.01)$, but not $25 \mu \mathrm{M}$ celecoxib (Fig. 6).

Expression of CD133 following celecoxib treatment. The protein expression of CD133 in 786-O and 786-O/S cells was quantified by western blot analysis (Fig. 7). The results demonstrated that the expression of CD133 was significantly higher in 786-O/S cells compared with 786-O cells (Fig. 7B; $\mathrm{P}<0.0001)$. When different concentrations $(10$ or $25 \mu \mathrm{M})$ of celecoxib were incubated with the cells, the expression of CD133 significantly decreased $(\mathrm{P}<0.001)$, particularly at a concentration of $25 \mu \mathrm{M}$ compared with in untreated 786-O/S cells (Fig. 7A).

\section{Discussion}

Several mechanisms are thought to be involved in the development of sunitinib resistance (17-25). These mechanisms 
A 1000 cells
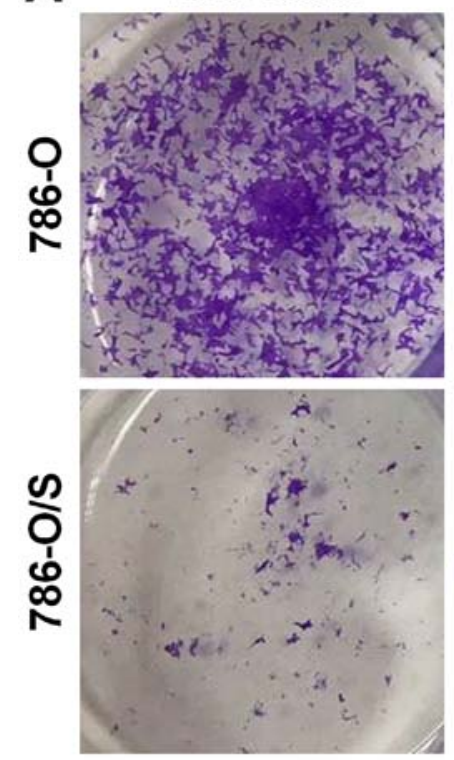

500 cells
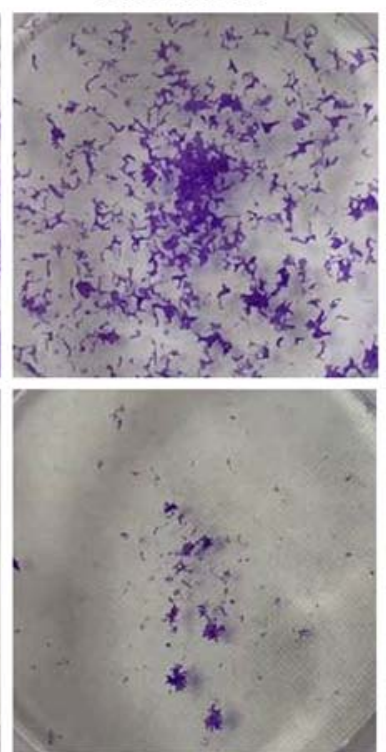

\section{0 cells}

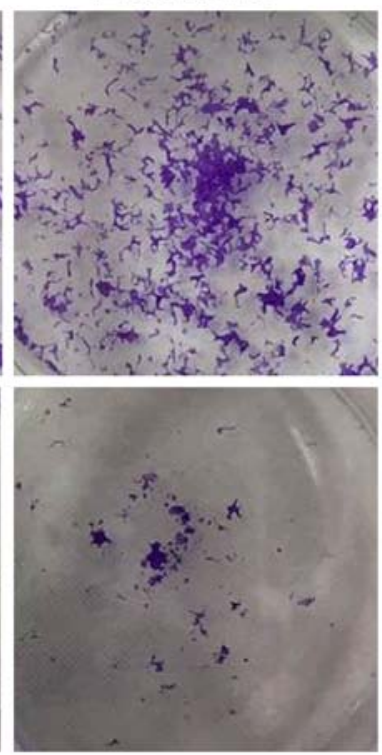

B

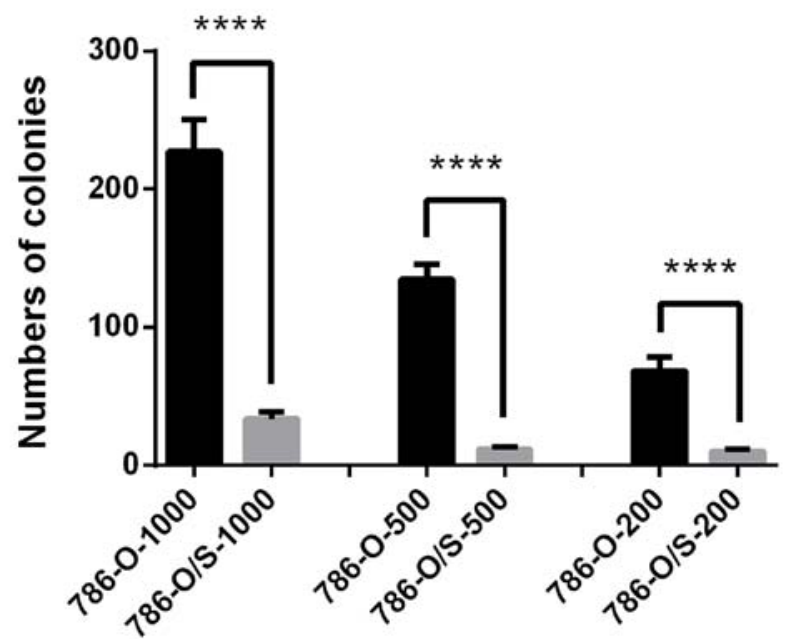

Figure 4. Influence of sunitinib on the colony formation ability of 786-O/S and 786-O cells at a density of 200, 500 and 1,000 cells for 15 days. (A) Photograph of colonies stained. (B) Statistical analysis of the number of colonies. Data are presented as the mean \pm standard error of the mean. ${ }^{* * * *} \mathrm{P}<0.0001$. $786-\mathrm{O} / \mathrm{S}$, sunitinib-resistant 786-O.

include: i) Lysosomal membrane permeabilization and autophagy; ii) antiangiogenic-therapy-induced hypoxia that may stimulate the expression of other proangiogenic factors, such as fibroblast growth factor and interleukin-8; iii) epithelial-to-mesenchymal transition regulation via epidermal growth factor receptor; iv) intrinsic resistance and multidrug resistance; v) sequestration of sunitinib in acidic lysosomes to reduce its cytoplasmic availability; and vi) alterations in the transcription of genes, including protein kinase X-linked, tau tubulin kinase 2, ribosomal protein S6 kinase $\alpha 4$, tyrosine-protein kinase receptor UFO, MET and interleukin 13 receptor subunit $\alpha 2$. The present study investigated the possible mechanism of sunitinib resistance via the COX-2-PGE2 signaling pathway.

In the early 1970s, Hamburger and Salmon (26) proposed the CSC theory by confirming that only a small number of cells in solid malignant tumors may further proliferate and form colonies following transplantation. This hypothesis implies that only a small number of CSCs possess the capacity for unlimited proliferation and tumor formation; thus, solid malignant tumors originate from a few CSCs. This theory has been studied further in acute myeloid leukemia, breast cancer and other cancer types $(27,28)$. CSCs in RCC have also been studied $(29,30)$. It has been reported that the expression of Bmi-1, a gene that may promote self-renewal of stem cells and whose mutation may lead to tumor initiation, is inversely proportional to the degree of RCC differentiation (31). Numerous characteristics of RCC are similar to those of stem cells (31), which indicates a possibility of the existence of renal CSCs. The surface marker of CSCs, CD133, also termed prominin 1, was initially identified as a cell surface antigen specific to hematopoietic stem cells (32). Bussolati et al (33) have reported the presence of CD133 in multipotent progenitor cells in the proximal tubules and Bowman's capsule in the kidneys of adults. Sun et al (34) demonstrated that CD133 expression is closely associated with the degree of tumor differentiation and TNM staging, including lymph node metastasis status. This observation 

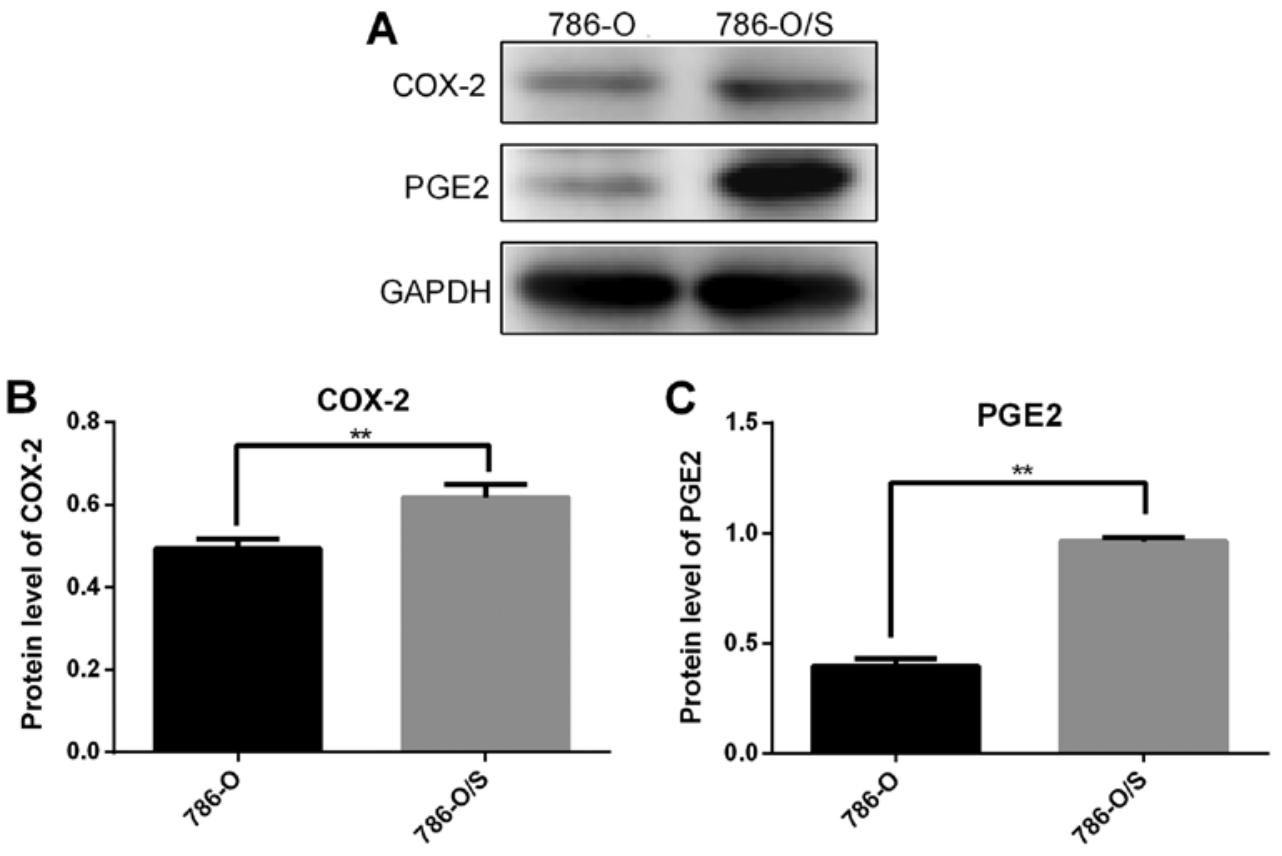

Figure 5. Evaluation of COX-2 expression and PGE2 synthesis in 786-O and 786-O/S cells. (A) COX-2 and PGE2 levels were determined by western blot analysis. (B) COX-2 expression was normalized to that of GAPDH. (C) PGE2 expression was normalized to that of GAPDH expression. Data are presented as the mean \pm standard error of the mean from three independent experiments. ${ }^{* *} \mathrm{P}<0.01 .786-\mathrm{O} / \mathrm{S}$, sunitinib-resistant 786-O; COX-2, cyclooxygenase 2; PGE2, prostaglandin E2.

A

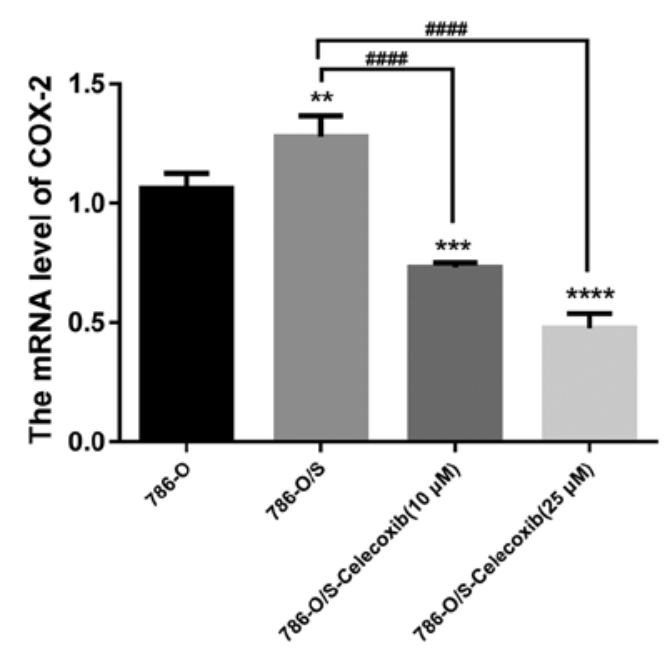

B

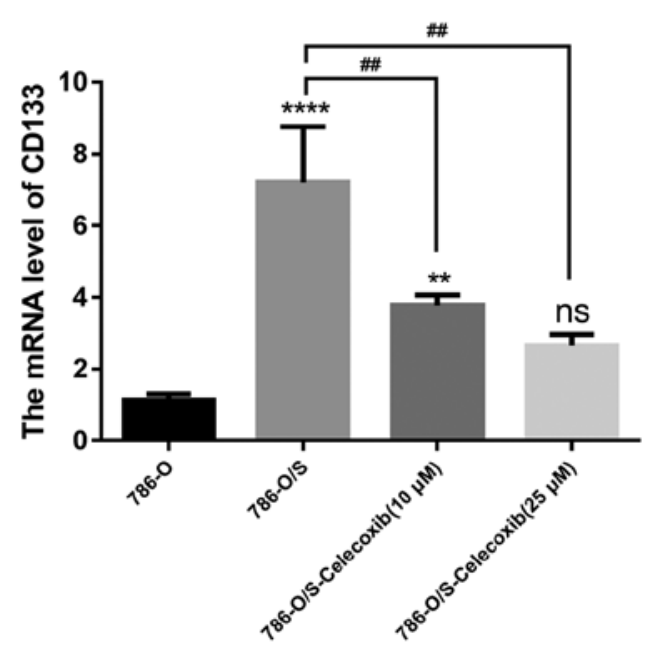

Figure 6. Detection of COX-2 (A) and CD133 (B) expression in 786-O and 786-O/S cells by reverse transcription-quantitative polymerase chain reaction following celecoxib treatment. Data are presented as the mean \pm standard error of the mean from three independent experiments (Compared with 786-O

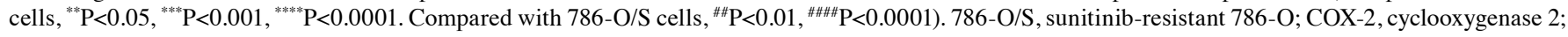
CD133, cluster of differentiation 133; ns, not significant.

was supported by Costa et al (35). The present study revealed the expression of CD133 in both 786-O and 786-O/S cells; however, CD133 expression was 24-fold higher in 786-O/S cells compared with 786-O cells. Therefore, the proportion of CSCs may notably increase among resistant cells, which suggests that CD133 may serve as a potential maker for the development of novel treatment strategies to target CSCs. A number of studies have demonstrated that CD133 may be inhibited by the Notch pathway in glioma stem cells and neuroblastoma cells $(36,37)$.
The enzyme COX-2 converts arachidonic acid to prostaglandin $\mathrm{G} 2$, which is later converted via peroxidase activity to prostaglandin $\mathrm{H} 2$, a precursor of other prostaglandins (38). The COX-2-PGE2 pathway is understood to perform an important function by increasing cell proliferation, promoting angiogenesis, inhibiting apoptosis, regulating cell adhesion and increasing the invasiveness of malignant cells (39). This pathway is seldom detected in human tissues under normal physiological conditions but may be activated in several solid malignant tumors, including colorectal, breast, prostate, skin, lung, bladder 
A
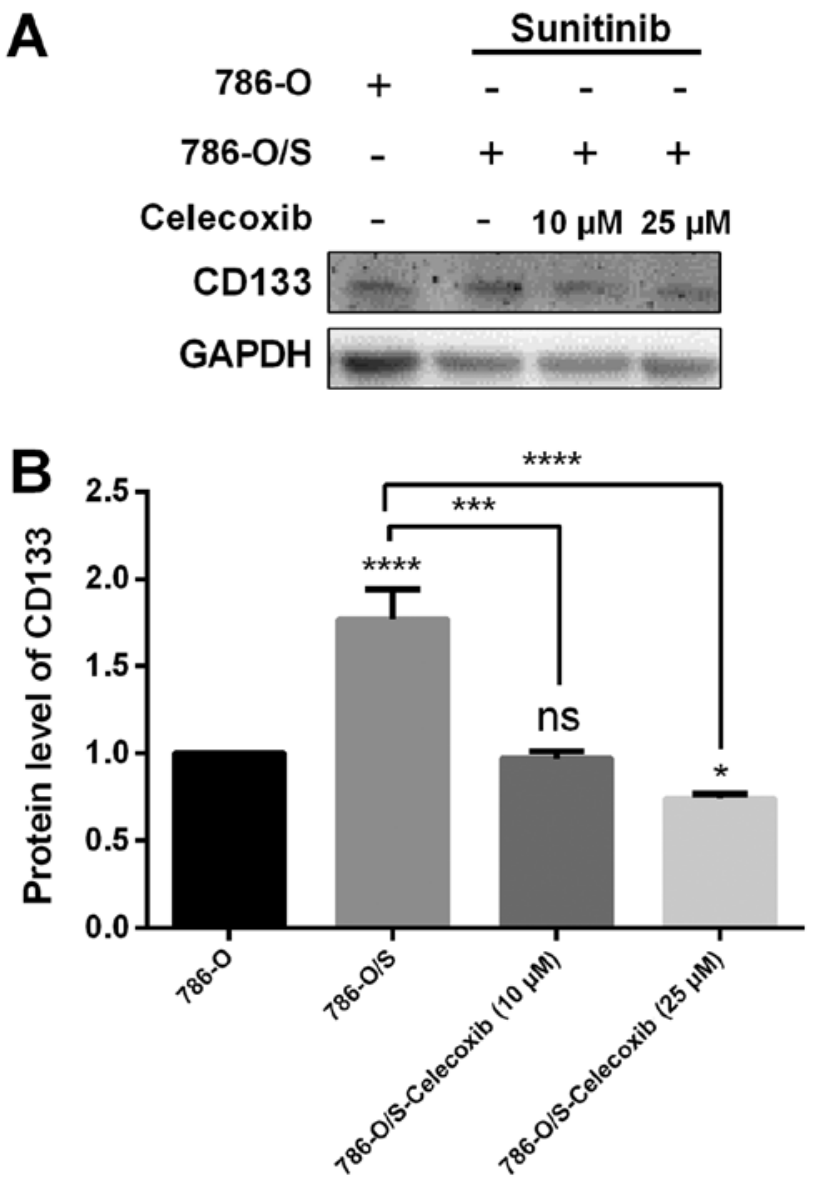

Figure 7. Determination of CD133 expression in 786-O and 786-O/S cells following celecoxib treatment. (A) CD133 levels were determined by western blot analysis. (B) The results were normalized to GAPDH expression. Data are presented as the mean \pm standard error of the mean from three independent experiments $\left({ }^{*} \mathrm{P}<0.05,{ }^{* * *} \mathrm{P}<0.001 .{ }^{* * * *} \mathrm{P}<0.0001\right.$ vs. $786-\mathrm{O} / \mathrm{S}$, sunitinib-resistant 786-O; CD133, cluster of differentiation 133; ns, not significant.

and pancreatic cancers (40). Yi et al (41) demonstrated that the expression levels of COX-2 in RCC were $10 \%$ higher compared with that in healthy renal tissue. Treatment of RCC with a combination of a tyrosine kinase inhibitor and COX-2 inhibitor has been rarely reported. Using a nude-mouse model of RCC, Wang et al (42) demonstrated that a COX-2 inhibitor may enhance the therapeutic effect of sunitinib and prolong the progression-free survival time. In addition, they revealed that the resistance to sunitinib is associated with strong expression of COX-2. Zhao et al (43) reported that a COX-2 inhibitor in combination with sunitinib is more effective compared with sunitinib or the COX-2 inhibitor alone in RCC-bearing mice. Therefore, combination therapy consisting of a COX-2 inhibitor and sunitinib may enhance the antitumor effect by reducing the number of immunosuppressive cells and regulating the tumor microenvironment. It can be hypothesized that sunitinib resistance in RCC may be mediated by the activation of the COX-2-PGE2 pathway. The current study identified that the expression of COX-2 and synthesis of PGE-2 were significantly higher in the resistant cell line compared with parental cells.

Celecoxib is widely used in the clinic. One study on COX-2 in non-selected patients with mRCC evaluated the effectiveness of celecoxib administered in conjunction with interferon- $\alpha$ and revealed that $20-30 \%$ of mRCC tumors exhibit maximal (3+) staining for COX-2 (44). Wang et al (42) identified that the combination of sunitinib with celecoxib resulted in a longer time to tumor progression compared with treatment with either agent alone or compared with untreated control animals in four models. Zhao et al (11) have also revealed that combination therapy consisting of sunitinib and celecoxib exerts improved curative effects against RCC compared with any monotherapy and identified that immunoregulatory cells may be involved in this phenomenon.

A number of studies have indicated that celecoxib inhibits tumor sphere formation by CD133 downregulation (45-48). COX-2 canfacilitateproliferation of CSCs (45).COX-2-dependent mechanisms of an inflammatory balance may be responsible for the treatment-resistant phenotype of CSCs (46). Annabi et al (46) revealed that COX-2 induction is associated with CD133 expression in human glioma cell lines and demonstrated that selective COX-2 inhibitors hold promise for further developments in the treatment of glioma. In in vivo and in vitro experiments, Ma et al (47) reported that CD133-associated tumorigenicity is significantly suppressed by celecoxib treatment. Furthermore, celecoxib combined with radiation strongly suppressed the growth of $\mathrm{CD}_{133^{+}}$glioblastoma stem-like cells. Similarly, Deng et al (48) reported a significant decrease in the levels of CD133 expression with increasing concentrations or increasing duration of treatment with celecoxib, as demonstrated in colon cancer HT29 cells. A gene expression microarray revealed that stemness-associated genes, including leucine-rich repeat-containing g-protein coupled receptor 5, octamer-binding transcription factor 4 , prominin 1 , prominin 2 , C-X-C receptor type 4, E2F transcription factor 8 and cyclin dependent kinase-2, were downregulated and differentiation-associated genes, including carcinoembryonic antigenic related cell adhesion molecule 5, growth/differentiation factor 15 , adipose differentiation-related proteins and intercellular adhesion molecule 1 , were upregulated (42).

In the current study, a drug-resistant RCC cell line (786-O/S) was established. The proliferation and migration abilities of 786-O/S were significantly higher compared with those of the control cell line, as evident from morphological observations, a scratch test and colony formation assay. Based on the close association between cancer resistance and CSCs, CD133 was assumed to be an important marker of CSCs in RCC. The current results demonstrated that the expression of CD133 was significantly higher in 786-O/S cells compared with the control cells. The expression levels of COX-2 and PGE2 were investigated, and were determined to be significantly increased in 786-O/S cells compared with the control cells. According to the present results, the expression of COX-2 increased in 786-O/S cells when COX-2 was inhibited by celecoxib. The expression of CD133 decreased at the same time. It could be hypothesized that COX-2 may, in part, be responsible for the drug resistance via CD133, which suggests that COX-2 may affect the activation of CSCs. Therefore, celecoxib should be considered for investigation within a clinical trial in the future; however, the mechanism of action of COX-2 inhibitors in the regulation of the cancer stem-like properties requires more in-depth study. In summary, COX-2 was identified to be overexpressed in sunitinib-resistant RCC cells and the COX-2-PGE2 signaling pathway may serve an important 
role in the maintenance of CSC characteristics of RCC cells that are closely associated with drug resistance.

\section{Acknowledgements}

The authors would like to thank Professor Haitao Niu and his team of Key Laboratory, Department of Urology and Andrology, Affiliated Hospital of Qingdao University for their help and technical support.

\section{Funding}

This study was supported by the National Natural Science Foundation of China (grant nos. 81672512, 81502195 and 81401899).

\section{Availability of data and materials}

The datasets used and/or analyzed during the current study are available from the corresponding author on reasonable request.

\section{Authors' contributions}

Conceptualization, LS and GZ; methodology, LL; formal analysis, LL and YL; resources, LL; data curation, XD; writing, original draft preparation, LL; writing, review and editing, LL; visualization, data analysis and paper revision, XM; funding acquisition, LS. All authors read and approved the final manuscript.

\section{Ethics approval and consent to participate}

Not applicable.

\section{Patient consent for publication}

Not applicable.

\section{Competing interests}

The authors declare that they have no competing interests.

\section{References}

1. Jemal A, Bray F, Center MM, Ferlay J, Ward E and Forman D: Global cancer statistics. CA Cancer J Clin 61: 69-90, 2011.

2. Chin AI, Lam JS, Figlin RA and Belldegrun AS: Surveillance strategies for renal cell carcinoma patients following nephrectomy. Rev Urol 8: 1-7, 2006.

3. National Cancer Institute: Previous version: SEER Cancer Statistics Review, 1975-2010. NCI, Bethesda, MD, 2013. https://seer.cancer.gov/archive/csr/1975_2010/.

4. Zhu H, Wang Z, Xu Q, Zhang Y, Zhai Y, Bai J, Liu M, Hui Z and $\mathrm{Xu}$ N: Inhibition of STAT1 sensitizes renal cell carcinoma cells to radiotherapy and chemotherapy. Cancer Biol Ther 13: 401-417, 2012.

5. Pantuck AJ, Zisman A and Belldegrun AS: The changing natural history of renal cell Carcinoma. J Urol 166: 1611-1623, 2001.

6. Gan HK, Seruga B and Knox JJ: Sunitinib in solid tumors. Expert Opin Investig Drugs 18: 821-834, 2009.

7. Abrams TJ, Lee LB, Murray LJ, Pryer NK and Cherrington JM: SU11248 inhibits KIT and platelet-derived growth factor receptor beta in preclinical models of human small cell lung cancer. Mol Cancer Ther 2: 471-478, 2003.
8. Mendel DB, Laird AD, Xin X, Louie SG, Christensen JG, Li G, Schreck RE, Abrams TJ, Ngai TJ, Lee LB, et al: In vivo antitumor activity of SU1 a novel tyrosine kinase inhibitor targeting vascular endothelial growth factor and platelet-derived growth factor receptors: Determination of a pharmacokinetic/pharmacodynamic relationship. Clin Cancer Res 9: 327-337, 2003.

9. Motzer R, Hutson TE, Tomczak P,Michaelson MD,BukowskiRM, Rixe O, Oudard S, Negrier S, Szczylik C, Kim ST, et al: Sunitinib versus interferon alfa in metastatic renal-cell carcinoma. N Engl J Med 356: 115-124, 2007.

10. Tabriz HM, Mirzaalizadeh M, Gooran S, Niki F and Jabri M: COX-2 Expression in renal cell carcinoma and correlations with tumor grade, stage and patient prognosis. Asian Pac J Cancer Prev 17: 535-538, 2016.

11. Zhao Q, Guo J, Wang G, Chu Y and Hu X: Suppression of immune regulatory cells with combined therapy of celecoxib and sunitinib in renal cell carcinoma. Oncotarget 8: 1668-1677, 2017.

12. Kaminska K, Szczylik C, Lian F and Czarnecka AM: The role of prostaglandin E2 in renal cell cancer development: Future implications for prognosis and therapy. Future Oncol 10: 2177-2187, 2014.

13. Liu LM, Sun HA, Li X, Chen Y, Wei BF and Li XJ: Cluster of differentiation 44- and octamer-binding transcription factor-4-positive stem-like osteosarcoma cells involved in tumor development. Oncol Lett 10: 273-276, 2015.

14. Li J, Zhong XY, Li ZY, Cai JF, Zou L, Li JM, Yang T and Liu W: CD133 expression in osteosarcoma and derivation of CD133 ${ }^{+}$ cells. Mol Med Rep 7: 577-584, 2012.

15. Ranji P, Salmani Kesejini T, Saeedikhoo S and Alizadeh AM: Targeting cancer stem cell-specific markers and/or associated signaling pathways for overcoming cancer drug resistance. Tumor Biol 37: 13059-13075, 2016.

16. Livak KJ and Schmittgen TD: Analysis of relative gene expression data using real-time quantitative PCR and the 2(-Delta Delta C(T)) method. Methods 25: 402-408, 2001.

17. Wiedmer T, Blank A, Pantasis S, Normand L, Bill R, Krebs P, Tschan MP, Marinoni I and Perren A: Autophagy inhibition improves sunitinib efficacy in pancreatic neuroendocrine tumors via a lysosome-dependent mechanism. Mol Cancer Ther 23: 2502-2515, 2017.

18. Giuliano S and Pagès G: Mechanisms of resistance to antiangiogenesis therapy. Biochimie 95: 1110-1119, 2013.

19. Gustafsson A, Fritz HKM and Dahlbäck B: Gas6-Axl signaling in presence of Sunitinib is enhanced, diversified and sustained in renal tumor cells, resulting in tumor-progressive advantages. Exp Cell Res 355: 47-56, 2017.

20. Lim SH, Hwang IG, Ji JH, Oh SY, Yi JH, Lim DH, Lim HY, Lee SJ and Park SH: Intrinsic resistance to sunitinib in patients with metastatic renal cell carcinoma. Asia Pac J Clin Oncol 13: 61-67, 2016.

21. Sarkadi B, Homolya L, Szakács G and Váradi A: Human multidrug resistance $\mathrm{ABCB}$ and $\mathrm{ABCG}$ transporters: Participation in a chemoimmunity defense system. Physiol Rev 86: 1179-1236, 2006.

22. Gotink KJ, Broxterman HJ, Labots M, de Haas RR, Dekker H, Honeywell RJ, Rudek MA, Beerepoot LV, Musters RJ, Jansen G, et al: Lysosomal sequestration of Sunitinib: A novel mechanism of drug resistance. Clin Cancer Res 17: 7337-7346, 2011.

23. Bender $\mathrm{C}$ and Ullrich A: PRKX, TTBK2 and RSK4 expression causes Sunitinib resistance in kidney carcinoma- and melanoma-cell lines. Int J Cancer 131: E45-E55, 2012.

24. Zhou L, Liu XD, Sun M, Zhang X, German P, Bai S, Ding Z, Tannir N, Wood CG, Matin SF, et al: Targeting MET and AXL overcomes resistance to sunitinib therapy in renal cell carcinoma. Oncogene 35: 2687-2697, 2016.

25. Shibasaki N, Yamasaki T, Kanno T, Arakaki R, Sakamoto H, Utsunomiya N, Inoue T, Tsuruyama T, Nakamura E, Ogawa O and Kamba T: Role of IL13RA2 in sunitinib resistance in clear cell renal cell carcinoma. PLoS One 10: e0130980, 2015.

26. Hamburger AW and Salmon SE: Primary bioassay of human tumor stem cells. Science 197: 461-463, 1997.

27. Bonnet D and Dick JE: Human acute myeloid leukemia is organized as a hierarchy that originates form a primitive hematopoietic cell. Nat Med 3: 730-737, 1997.

28. Al-Hajj M, Wicha MS, Benito-Hernandez A, Morrison SJ and Clarke MF: Prospective identification of tumorigenic breast cancer cells. Proc Natl Acad Sci USA 100: 3983-3988, 2003.

29. Gedye C, Sirskyj D, Lobo NC, Meens J, Hyatt E, Robinette M, Fleshner N, Hamilton RJ, Kulkarni G, Zlotta A, et al: Cancer stem cells are underestimated by standard experimental methods in clear cell renal cell carcinoma. Sci Rep 6: 25220, 2016. 
30. Yuan ZX, Mo J, Zhao G, Shu G, Fu HL and Zhao W: Targeting strategies for renal cell carcinoma: From renal cancer cells to renal cancer stem cells. Front Pharmacol 10: 423, 2016.

31. Kozakowski N, Soleiman A and Pammer J: BM I-1 expression is inversely correlated with the grading ofrenal cell carcinoma. Pathol Oncol Res 14: 9-13, 2008.

32. Kim K, Ihm H, Ro JY and Cho YM: High-level expression of stem cell marker CD133 in clear cell renal cell carcinoma with favorable prognosis. Oncol Lett 2: 1095-1100, 2011.

33. Bussolati B, Bruno S, Grange C, Buttiglieri S, Deregibus MC, Cantino D and Camussi G: Isolation of renal progenitor cells from adult human kidney. Am J Pathol 166: 545-555, 2005.

34. Sun C, Song H, Zhang H, Hou C, Zhai T, Huang L and Zhang L: CD133 expression in renal cell carcinoma (RCC) is correlated with nuclear hypoxia-inducing factor $1 \alpha(\mathrm{HIF}-1 \alpha)$. J Cancer Res Clin Oncol 138: 1619-1624, 2012.

35. Costa WH, Rocha RM, Cunha IW, Fonseca FP, Guimaraes GC and Zequi Sde C: CD133 immunohistochemical expression predicts progression and cancer-related death in renal cell carcinoma. World J Urol 30: 553-558, 2012.

36. Fan X, Matsui W, Khaki L, Stearns D, Chun J, Li YM and Eberhart CG: Notch pathway inhibition depletes stem-like cells and blocks engraftment in embryonal brain tumors. Cancer Res 66: 7445-7452, 2006.

37. Wang J, Wang H, Li Z, Wu Q, Lathia JD, McLendon RE, Hjelmeland $\mathrm{AB}$ and Rich JN: c-Myc is required for maintenance of glioma cancer stem cells. PLoS One 3: e3769, 2008.

38. Taketo MM: Cyclooxygenase-2 inhibitors in tumorigenesis (part I). J Natl Cancer Inst 90: 1529-1536, 1998.

39. Tsujii M, Kawano S and DuBois RN: Cyclooxygenase-2 expression in human colon cancer cells increase metastatic potential. Proc Nad Acad Sci USA 94: 3336-3340, 1997.
40. Zha S, Yegnasubramanian V, Nelson WG, Isaacs WB and De Marzo AM: Cyclooxygenases in cancer: Progress and perspective. Cancer Lett 215: 1-20, 2004.

41. Yi S, Wang CP and Zeng FQ: Expression levels of COX-2 and MMP-14 in renal cell carcinoma and clinical significance. Modern Hospital 17: 77-80, 2017.

42. Wang X, Zhang L, O'Neill A, Bahamon B, Alsop DC, Mier JW, Goldberg SN, Signoretti S, Atkins MB, Wood CG and Bhatt RS: Cox-2 inhibition enhances the activity of sunitinib in human renal cell carcinoma xenografts. Br J Cancer 108: 319-326, 2013.

43. Zhao Q, Hu XY, Wang GM, Guo JM and Chu YW: COX-2 inhibitor enhances the activity of sunitinib in renal cell carcinoma-bearing mice and its mechanism. Fudan Univ J Med Sci 43: 527-533, 2016.

44. Rini BI, Weinberg V, Dunlap S, Elchinoff A, Yu N, Bok R, Simko J and Small EJ: Maximal COX-2 immumostaining and clinical response to celecoxib and interferon alpha therapy in metastatic renal cell carcinoma. Cancer 106: 566-575, 2006.

45. Sharma V, Dixit D, Ghosh S and Sen E: Cox-2 regulates the proliferation of glioma stem like cells. Neurochem Int 59: 567-571, 2011.

46. Annabi B, Laflamme C, Sina A, Lachambre MP and Béliveau R: A MT1-MMP/NF-kappaB signaling axis as a checkpoint controller of COX-2 expression in CD133(+) U87 glioblastoma cells. J Neuroinflammation 6: 8, 2009.

47. Ma HI, Chiou SH, Hueng DY, Tai LK, Huang PI, Kao CL, Chen YW and Sytwu HK: Celecoxib and radioresistant glioblastoma-derived $\mathrm{CD} 133^{+}$cells: Improvement in radiotherapeutic effects. J Neurosurg 114: 651-662, 2011.

48. Deng Y, Su Q, Mo J, Fu X, Zhang Y and Lin EH: Celecoxib downregulates CD133 expression through inhibition of the Wnt signaling pathway in colon cancer cells. Cancer Invest 31: 97-102, 2013. 